\title{
ECOLE POLYTECHNIQUE
}

\section{BANKING AND BACKLOADING EMISSION PERMITS}

\author{
Corinne CHATON \\ Anna CRETI \\ Benoît PELUCHON
}

November 2013

Cahier $n^{\circ} 2013-30$

\section{DEPARTEMENT D'ECONOMIE \\ Route de Saclay \\ 91128 PALAISEAU CEDEX \\ (33) 169333033 \\ http://www.economie.polytechnique.edu/ \\ mailto:chantal.poujouly@polytechnique.edu}




\title{
Banking and backloading emission permits*
}

\author{
Corinne $\mathrm{CHATON}^{\dagger} \quad$ Anna $\mathrm{CRETI}^{\ddagger} \quad$ Benoît PELUCHON $^{\S}$
}

November 2013

\begin{abstract}
In this article we focus on carbon price dynamics, more specifically the impact of a policy envisaged by the European Commission to increase the $\mathrm{CO}_{2}$ price. This policy consists of removing a share of the allowances allocated for a period in order to reallocate some or all of them during the following period. To analyze the impact of this backloading we determine the $\mathrm{CO}_{2}$ market equilibrium with and without the policy, considering not only the market for permits but also the output market of regulated sectors. We propose a two-period model without uncertainty, where the market for permits is perfectly competitive, and the output market can be either competitive or oligopolistic. First, we define the condition for which banking from one period to another is optimal. This condition, that is the absence of arbitrage opportunities $(A O A)$, depends on not only from the per period initial allocation but also on production market fundamentals. When this condition is satisfied, the market for emission is shown intertemporally efficient. Second, we show that the "back-loading" policy may be such that the $A O A$ is no longer verified and thus create inefficiencies or being ineffective.

JEL Code: D4, Q58 - Key words: $\mathrm{CO}_{2}$ prices, banking, backloading, ETS reform.
\end{abstract}

\footnotetext{
${ }^{*}$ We thank Khalil Helioui for its comments and suggestions. The views, assumptions and opinions expressed in this paper are those of the author and do not necessarily reflect the official policy or position of EDF.

${ }^{\dagger}$ EDF R\&D, FiME (Finance for Energy Market Research Centre) and CABREE (Centre for Applied Business Research in Energy and the Environment). Phone: + 331476536 46. Fax: +33147653734 .

${ }^{\ddagger} \mathrm{CECO}$, Ecole Polytechnique.

${ }^{\S} \mathrm{EDF}$ R\&D.
} 


\section{Introduction}

The EU-ETS has undergone significant changes since its inception in 2005. During the first phase (2005-2007) the permit price collapsed and reached zero during the last months of 2007, when it became clear that too much allowances were issued (see Figure 4 in Appendix 9.1). In response, the Climate and Energy Package, adopted in December 2008, authorized the banking of permits between different phases, ie the ability to use permits issued in one year (vintage) for compliance in the years following. Banking was already authorized between different years inside a phase and borrowing, i.e. the possibility to use permits issued for a specific year for compliance in the preceding year, is allowed within a phase. Therefore, even if a phase is "long" (total emissions lower than the sum of allowances), the value of permits is positive because of the possibility to use them in the next phase. That was the situation at the beginning of 2013: due to the European sovereign crisis, the emission permit price on the EU-ETS had fallen to levels considered too low to have an impact on investment decisions. In fact, the price did not reflect the value of using phase 2 allowances during phase 3, since 2012 emissions was estimated below the cap for that year and there was a surplus of permits on the market. This situation shows the importance of EU-ETS temporal flexibilities in order to understand how prices are formed, especially when those features are being replicated in other markets currently being introduced around the world (Australian, California, New Zealand but also China and South Korea). However, the 2008 recession and the euro crisis beginning in 2010 have seen much lower emissions than what was expected when emissions reductions targets were defined. As a consequence, a permits surplus has grown in importance and is now expected by the European Commission to reach 2000 Mt in 2013 (European Commission, 2012). The carbon price has fallen a lot and is now at levels deemed insufficient to induce investments in cleaner production capacities. Along this, repeated efforts by the Commission to define targets for 2030 or beyond have backfired under political opposition by coal-dependent countries. The backloading proposal is a mean to prop up the price that allows to get around this opposition. The ETS amendment approved on July 3rd 2013 by the European Parliament states that 900 million of permits will be withdrawn from auctions between 2013 and 2015, and reintroduced in 2019 and 2020. During fall 2013, the amendment has moved to the European Council to discuss several features, including how to connect backloading with long-term objectives of the EU-ETS. As such, a backloading measure still implies a high uncertainty on the final quantity of permits effectively supplied during the last years of phase 3, since the possibility exists that withheld permits are not completely re-injected in the market. This means that expected permits supply would be lower than phase 3 cap. How do those features affect the price dynamic in the EU-ETS? In order to answer that question it is necessary to go beyond the 
analysis found in the literature and build a model in which the rules characterizing its intertemporal flexibilities are precisely handled. Moreover such measures, often described as "capacity adjustment mechanisms" can be found in market designs of emissions markets currently being set-up in different parts of the world (Australia, California, South Korea, China to name the most advanced projects). The goal of the present paper is to investigate how and when such an operation may succeed.

To do so, we consider first the specificities of banking. This latter is allowed inside a phase and between phases: a permit from a given vintage may be used for all following compliances. This set-up also implies that borrowing is partly allowed whithin a phase: since allowances for vintage $t$ are issued before the compliance for vintage $t-1$, it is possible to surrender them, in effect allowing to borrow permits in advance (for a presentation of these rules see Carmona, Fehr, Hinz (2009) or Peluchon (2011)). The gradual evolution towards auctioning does not alter this possibility as long as enough future vintages are sold in advance (phase 3 permits have begun to be auctioned) 1 .

Our work is related to papers studying temporal flexibilities in permits markets. The first articles to tackle this issue are Rubin (1996) and Cronshaw and Kruse (1996). While the latter shows that banking leads to the least-cost solution, provided that no firm is subject to a rate of return regulation, the former extends the model and provides a rigorous treatment allowing for the inclusion or not of borrowing. Rubin finds the necessary conditions for a perfectly competitive permits market equilibrium to exist, without uncertainty. The firms must comply with a cap and each one must decide: (1) the level of their emissions at each time, knowing that the less they emit, the more it costs (the cost function may be different between firms); (2) the quantity of permits bought/sold at each time. The equilibrium is found by means of optimal control in continuous time and finite horizon, with a terminality condition such that if a firm holds a permit at the terminal period, its value is zero. Banking and borrowing allow firms to equalize their present value marginal abatement costs, and, as a consequence the permit price grows at the discount rate (Hotelling's rule). If borrowing is not allowed and the constraint is binding, then the permit price will grow at a lower rate, reflecting the fact that a firm would need to borrow permits from the future in order to equalize its present value marginal abatement costs. Rubin also obtains the growth path of equilibrium emissions, which allows him to conclude that banking allows for less social damages, when the cap decreases with time and the damage function is convex and cumulative damage is the integral of damages in all time periods. This helps to highlight the social benefits coming with intertemporal flexibility: firms have an incentive to reduce their emissions sooner than

\footnotetext{
${ }^{1}$ For a survey on banking literature, see Chevalier (2012), whereas a more general review of the literature about cap and trade systems can be found in Taschini (2009).
} 
without banking, because they are "saving" their reduction in the form of permits for a future more constrained. Kling and Rubin (1997) show that this property does not necessarily imply that banking and borrowing are socially optimal, when taking into account the fact that lower emissions mean higher production costs for price-taking firms (the price of the good produced is exogenous, no demand is represented in the model). They propose to modify the banking-borrowing provisions in order to lower social costs by introducing a "discount ratio" for borrowed permits (i.e. firms would have to pay more when they borrow).

Schennach (2000) treats equilibrium on the emission market in the same way that Rubin (1996) but in infinite horizon. Schennach shows that, when borrowing is disallowed and when abatement marginal cost does not increase faster than the discount rate the only incentive to bank allowances is the fact that there are different phases with a decreasing cap. Banking allows firms to smooth the evolution of those costs between the two phases by "saving" permits during the first phase and depleting that stock until a finite time in the second phase, after which permit price only changes because of changes in costs. She provides explicit solutions for the optimal emissions path and the permit price when borrowing is not allowed by restricting abatement marginal cost to a linear function. Sensitivity analysis can thus be performed when abatement cost decrease exogenously because of the introduction of a new low-emissions fuel or of a new technology. This framework is then extended to uncertainty. This latter case implies that a kind of convenience yield exists: the expected permit price grows at a lower rate than the discount rate, because of the borrowing constraint. Maeda (2004) explicitly introduces a futures market with uncertainty and shows that prices depend of the distribution between pure traders and regulated actors, when both are risk-averse and the pure traders use permit futures to hedge an exogenous but correlated risk. The question of market power in emissions permits market when there is banking has been studied by Montero and Liski (2005) and a review of the different connected questions can be found in the thorough review by Montero (2009). In all preceding articles, the regulated market equilibrium is never introduced 2. Baseline emissions are always exogenous and the decisions are how much and when to abate emissions. As such, it is difficult to analyze when and why Hoteling's rule is not valid, since it is almost always the case, as long as caps are decreasing and baseline emissions at least non-decreasing. Moreover, the sensivity analysis performed by Schennach cannot be thorough since marginal abatement costs variations have to be interpreted either as baseline emissions shocks or technology shocks. Being able to distinguish between causes affecting the output market whose emissions are regulated is important if we want to assess the impact of backloading measures

\footnotetext{
${ }^{2}$ Papers which focuses on both the permit market and the output market (see for exemple Hintermann (2009)) do not take banking into account.
} 
described in the following paragraph.

The remainder of this paper is organised as follows. The model is presented in section 2. In section 3, we show that the no intertemporel arbitrage opportunity condition (equivalent to Hotelling's rule) depends on the fundamentals of the output market. Section 4 focuses on $\mathrm{CO}_{2}$ prices. When the no-arbitrage opportunity condition is fulfilled, intertemporal efficiency is achieved on the emissions market, since it implies that firms can minimize the sum of environmental discounted costs. Moreover, we show that rules such a cap decreasing in a pre-determined percentage every year can be inefficient as this rule might create inefficiencies in the market for permits. In section 5, we discuss how backloading impact the permit market. We define a quota threshold such that below this threshold the backloading policy has no effect, and above this threshold efficiency is not guaranteed since present value carbon prices are no longer equal. If only a share of permits backloaded is re-injected in the market, then total cap is modified and prices are higher in both cases.

\section{The model}

The model focuses on the determination of prices for emissions permits. To enhance the clarity of the analysis, we do not consider uncertainty. We consider two periods, corresponding to two successive phases of a market for permits. The discount rate between the two periods is $r$. For any variable or parameter $y$ relating to the first period, $y^{\prime}$ relates to the second one. In the following, we detail our modelling assumptions.

Demand and production. There are $n$ symmetric ${ }^{3}$ firms which compete in quantities in a market for a homogeneous good. The demand for the produced good is elastic. We use a linear inverse demand function $p=b-d n q$ for the first period $\left(p^{\prime}=b^{\prime}-d^{\prime} n q^{\prime}\right.$ for the second period).

A firm chooses $q$ in the first period and $q^{\prime}$ in the second period at a cost assumed linear, for ease of calculation

$$
C\left(q, q^{\prime}\right)=c q+\frac{1}{1+r} c^{\prime} q^{\prime}
$$

Carbon Emissions and Abatement Technologies. When the firm produces $q$ in the first period ( $q^{\prime}$ in the second period) it emits an amount $e(q)$ of pollution in the first period $\left(e^{\prime}\left(q^{\prime}\right)\right.$ in the second period) such that $e(q)=e_{0} q$

\footnotetext{
${ }^{3}$ The firms use the same polluting technology as well as the same abatement technology in order to reduce their pollution.
} 
$\left(e^{\prime}\left(q^{\prime}\right)=e_{0}^{\prime} q^{\prime}\right.$ respectively) where $e_{0}>0$ and $e_{0}^{\prime}>0$ are exogenous factors associated to the production technologies. For each period, each firm has the option of reducing emissions (from $e_{0}$ to $\epsilon$ in the first period and from $e_{0}^{\prime}$ to $\epsilon^{\prime}$ in the second period) bearing an cost $\left(e_{0}-\epsilon\right) q$ in the first period $\left(\left(e_{0}^{\prime}-\epsilon^{\prime}\right) q^{\prime}\right.$ in the second period). This cost is mainly related to the cost of fuel-switching which is a short-term cost because production technologies are already in place. Producer change production technology if this cost is lower than the gain obtained through the use of cleaner technology.

Carbon Quotas and Emissions. Each period, a firm has to hold a permit in order to pollute one unit. During each period the total volume of emissions is limited by the initial allocation $A$ in the first period ( $A^{\prime}$ in the second period with $\left.A^{\prime} \leq A\right)$, whose amount is decided by the regulator. The emissions units can be traded and sold in a market of emission permits in which firms are price-taker and competition is perfect. A producer can buy at a price $\sigma$ per unit, $z$ permits in the first period ( $z^{\prime}$ permits at a price $\sigma^{\prime}$ per unit in the second period). For each period, he must have at least as many permits as units that emits. In the first period, he can store permits, $\bar{z}$, in order to use it in the second period (banking). Permits are stored at zero costs. We assume that borrowing is impossible, therefore $\bar{z} \geq 0$, and that all inventories have to be emptied by the end of the second period $4^{4}$

Firms' profits. Firms' profits can be decomposed into three terms:

- net revenues from selling in the output market, $(p-c-\sigma \epsilon) q+\frac{1}{1+r}\left(p^{\prime}-c^{\prime}-\right.$ $\left.\sigma^{\prime} \epsilon^{\prime}\right) q^{\prime}$

- cost of emissions after abatement, $-\left(e_{0}-\epsilon\right) q-\frac{1}{1+r}\left(e_{0}^{\prime}-\epsilon^{\prime}\right) q^{\prime} \leq 0$ and

- net revenues from banking (trading) on the $\mathrm{CO}_{2}$ permits (market), $\left(\frac{\sigma^{\prime}}{1+r}-\sigma\right) \bar{z}$.

Notice that the sign of the last term depends on the value of the demand and cost parameters and on the $\mathrm{CO}_{2}$ quota. In particular, quotas from the first period may not be enough to allow banking. In this case $\frac{\sigma^{\prime}}{1+r}>\sigma$. In the following, we determine conditions on $A$ and $A^{\prime}$ such as in equilibrium there is no arbitrage opportunity $\left(\frac{\sigma^{\prime}}{1+r}=\sigma\right)$.

\footnotetext{
${ }^{4}$ For similar setting where firms in the output market can be competitive (if $n$ tends to infinity and the demand is inelastic) or oligopolisitc and no market power exists in the allowance market, see Requate (2005).
} 
Banking. Banking is a trading tool allowing to earn profits from the price spread in the two phases of the market for permits. This is similar to physical storage that smooths the seasonal price differential. Banking helps suppliers to meet their obligation ${ }^{5}$ (have as many permits as emissions) at a lower cost.

\section{Solving the model}

Equilibrium conditions on the CO2 market. Given the assumptions above, the equilibrium conditions on the $\mathrm{CO}_{2}$ market are as follows

$$
\begin{aligned}
z & =\epsilon q+\bar{z} \\
z^{\prime} & =\epsilon^{\prime} q^{\prime}-\bar{z} \\
n z & \leq A \\
n z^{\prime} & \leq A^{\prime}
\end{aligned}
$$

Equations (2) and (3) represent the fundamental relationship between banking in the market for permits and the output market.

Equilibrium prices of emission permits and supply. To determine the equilibrium price in the market for $\mathrm{CO}_{2}$ permits, in a first step, we determine the market equilibrium of the good considering permit prices $\left(\sigma\right.$ and $\left.\sigma^{\prime}\right)$ exogenous, then in second step, we calculate the equilibrium on the $\mathrm{CO}_{2}$ market.

Firms maximize their profit given by

$$
\begin{aligned}
\Pi= & (p-c-\sigma \epsilon) q+\frac{1}{1+r}\left(p^{\prime}-c^{\prime}-\sigma^{\prime} \epsilon^{\prime}\right) q^{\prime} \\
& -\left(e_{0}-\epsilon\right) q-\frac{1}{1+r}\left(e_{0}^{\prime}-\epsilon^{\prime}\right) q^{\prime}+\left(\frac{\sigma^{\prime}}{1+r}-\sigma\right) \bar{z} .
\end{aligned}
$$

We solve the model as follow. We find the symmetric Nash equilibrium on the final market the quantities produced by a firm and get the total quantities

\footnotetext{
${ }^{5}$ Since traders do not have this obligation, emission permits are more valuable for a supplier than for a trader. As a consequence, traders can be active only if some suppliers are financially constrained. Since the environment is certain, if producers are not financially constrained so pure traders do not exist (the producers have the highest willingness to pay). If during the first period the producers do not have the financial capacity to store permits then the traders can act as a portfolio manager of permits if producers have the financial capacity to buy them during the second period. In this case, (with a discount rate equal for each type of agent) the equilibrium obtained is identical to that obtained without financing constraints. The pure traders act as an intermediary (on a market that is considered competitive).
} 
produced in the two periods

$$
\begin{aligned}
q & =\frac{b-c-\sigma \epsilon-\left(e_{0}-\epsilon\right)}{(1+n) d} \\
q^{\prime} & =\frac{b^{\prime}-c^{\prime}-\sigma^{\prime} \epsilon^{\prime}-\left(e_{0}^{\prime}-\epsilon^{\prime}\right)}{(1+n) d^{\prime}} .
\end{aligned}
$$

The equilibrium on the $\mathrm{CO}_{2}$ market implies (4), (5) and

$$
\frac{\partial \Pi}{\partial \bar{z}}=\frac{\sigma^{\prime}}{1+r}-\sigma=0 \text { if } \bar{z}>0
$$

For ease of calculations, in the following Sections, we assume $c^{\prime}=c, b^{\prime}=b$, $d^{\prime}=d$ and $\epsilon=\epsilon^{\prime}=e_{0}=e_{0}^{\prime}$ (see the Appendix 9.3 for the general case).

\section{Equilibrium.}

If the number of permits $A+A^{\prime}$ is such as

$$
A+A^{\prime}<\frac{n}{n+1} \frac{2(b-c) \epsilon}{d}
$$

then the firms are constrained. If furthermore

$$
(1+r) A-A^{\prime}>\frac{n}{n+1} \frac{(b-c) r \epsilon}{d}
$$

there is an opportunity to store permits and at equilibrium the abscence of arbitrage opportunities, $\mathrm{AOA}$ is characterized by $\sigma^{\prime *}=(1+r) \sigma^{*}$ and equilibrium is defined by

$$
\begin{aligned}
q^{*} & =\frac{A+A^{\prime}}{n(2+r) \epsilon}+\frac{r(b-c)}{(n+1)(2+r) d}, \\
q^{*} & =(1+r) \frac{\left(A+A^{\prime}\right)}{n(2+r) \epsilon}-\frac{r(b-c)}{(n+1)(2+r) d}, \\
\bar{z}^{*} & =\frac{(1+r) A-A^{\prime}}{n(2+r)}-\frac{r(b-c) \epsilon}{(n+1)(2+r) d}, \\
\sigma^{*} & =\frac{2(b-c)}{(2+r) \epsilon}-\frac{(n+1)\left(A+A^{\prime}\right) d}{n(2+r) \epsilon^{2}}, \\
\sigma^{*} & =(1+r) \sigma^{*} .
\end{aligned}
$$

The condition on $A$ and $A^{\prime}$ such that firms are constrained by the number of permits on the two periods combined (Equation (9) ) and the optimality condition 
of the banking (Equation (10) imply firms are "quota constrained" in period 1, i.e.

$$
A<\frac{n}{n+1} \frac{(b-c) \epsilon}{d} .
$$

Since by assumption $A^{\prime}<A$, Equation (15) implies firms are "quota constrained" in period 2, i.e.

$$
A^{\prime}<\frac{n}{n+1} \frac{(b-c) \epsilon}{d} .
$$

If there is no banking, firms are "quota constrained" during the second period if Inequality $(16)$ is verified and during the first period if Inequality $(15)$ is verified ${ }^{6}$

Proposition 1. - No-arbitage condition - If the optimality condition of the banking (Equation (10)) does not hold then the equation of AOA is not verified. In this case, banking is not the optimal and since by assumption borrowing is impossible, carbon prices are such that $\sigma^{\prime}<(1+r) \sigma$ and the equilibrium is defined by

$$
\begin{aligned}
q_{n b} & =\frac{A}{n \epsilon}, \\
q_{n b}^{\prime} & =\frac{A^{\prime}}{n \epsilon}, \\
\sigma_{n b} & =\frac{b-c}{\epsilon}-\frac{1+n}{n} \frac{d A}{\epsilon^{2}}, \\
\sigma_{n b}^{\prime} & =\frac{b-c}{\epsilon}-\frac{(1+n)}{n} \frac{d A^{\prime}}{\epsilon^{2}} .
\end{aligned}
$$

No banking. Equations $(17)$ - 20) define also equilibrium in the case where the banking is not allowed and the firms are "quota constrained" in period 1 (Equation (15) verified). In this case, we have $\sigma_{n b}^{\prime}>\sigma_{n b}$. Indeed,

$$
\sigma_{n b}^{\prime}=\sigma_{n b}+\frac{\left(A-A^{\prime}\right)(1+n) d}{n \epsilon^{2}}>\sigma_{n b}
$$

The difference between the prices of permits $\left(\sigma_{n b}^{\prime}-\sigma_{n b}\right)$ is an increasing function of the elasticity of the demand. In competition on the market of the good $(n$ tends to infinity) the prices of permits are $\sigma_{n b}=\frac{(b-c)}{\epsilon}-\frac{A d}{\epsilon^{2}}$ and $\sigma_{n b}^{\prime}=\frac{(b-c)}{\epsilon}-\frac{A^{\prime} d}{\epsilon^{2}}$. These prices are increasing functions of the number of firms. Indeed, when this number is higher, the quantity produced becomes more important and consequently the volume of emissions is increasing therefore the need for permits is more important.

\footnotetext{
${ }^{6}$ Inegality (15) implies $\sigma>1$, or $\sigma e_{0} q>\sigma \epsilon q+\left(e_{0}-\epsilon\right) q$ that is a firm will adopt the new technology including adoption costs. Said differently, allocations $A$ and $A^{\prime}$ give incentives to adopt the technology with the abatment factor $\epsilon$.
} 
If the number of permits is sufficiently low $\left(A<\frac{n}{2(n+1)} \frac{(b-c) \epsilon}{d}, A^{\prime}<\frac{n}{2(n+1)} \frac{(b-c) \epsilon}{d}\right)$, the prices of permits decrease with the polluting factor $\epsilon$ and when $\frac{n}{2(n+1)} \frac{(b-c) \epsilon}{d}<A<$ $\frac{n}{(n+1)} \frac{(b-c) \epsilon}{d}$ and $\frac{n}{2(n+1)} \frac{(b-c) \epsilon}{d}<A^{\prime}<\frac{n}{(n+1)} \frac{(b-c) \epsilon}{d}$ the prices of permits increase with $\epsilon$.

If the firms are constrained only on the second period and the banking is not allowed, the quantity produced by each firm in the first period is

$$
q=\frac{b-c}{(1+n) d}
$$

the $\mathrm{CO}_{2}$ permit price in the first period is $\sigma=0$, the $\mathrm{CO}_{2}$ permit price in the second period is defined by the Equation 20 and the resulting outputs sold by each firm on the second period by the Equation (18).

No constraint. If the firms are not constrained by the permits allocation, the quantities produced by each firm are

$$
q=q^{\prime}=\frac{b-c}{(1+n) d}
$$

and the $\mathrm{CO}_{2}$ permit prices are

$$
\sigma=\sigma^{\prime}=0
$$

Equilibrium properties. Equation (13) shows that banking decreases with a factor that depends from the parameter or demand and costs of the output market $\left(\frac{r(b-c) \epsilon}{(n+1)(2+r) d}>0\right)$. Indeed, production of goods offers flexibility and weakens the borrowing constraint. Combining Equations (11) and (12) yields

$$
q^{*}=(1+r) q^{*}-\frac{r(b-c)}{(1+n) d}
$$

Consequently $q^{*}<(1+r) q^{*}$. Since banking links the productions of the two periods, if the parameters of demand and costs are the same from one period to another, while the production of the second period will be at best equal to the capitalized production of the first period. Moreover, given that we are in the case where firms are constrained by the number of permits, the total output $\left(n\left(q^{\prime *}+q^{*}\right)\right)$ depends only on the number of permits $\left(A+A^{\prime}\right)$ and emission factor $\epsilon$. Indeed, the Equations (11) and (12) provide

$$
q^{\prime *}+q^{*}=\frac{A+A^{\prime}}{n \epsilon} .
$$

When $n$ tends to infinity (competitive markets) then $q^{* *}$ tends to $(1+r) q^{*}$. 
Remark 1. The equilibrium quantities with (Equations (11) - (12)) and without banking (Equations (17) - 18)) and the optimality condition of the banking (Equation (10)) provide

$$
(1+r) q^{*}+q^{\prime *}<(1+r) q_{n b}+q_{n b}^{\prime} .
$$

Equation (27) does not mean that there is strategic restriction of the output.

Obviously, the profit of a firm obtained when there is banking, $\Pi^{*}$ is greater than the profit without banking, $\Pi_{n b}$. The ability to store permits offer flexibility to the firm. This flexibility has a value that can be quantified. Indeed,

$$
\Pi^{*}=\Pi_{n b}+P
$$

where

$$
P=\frac{\left((1+r) A-A^{\prime}\right)}{n^{2}(1+r)(2+r) \epsilon^{2}}\left[(1+n)\left((1+r) A-A^{\prime}\right) d-n(b-c) r \epsilon\right] .
$$

The terms in brackets are those of the optimality condition of the banking (Equation (10). As a result, if the banking is optimal Equation (10) is satisfied then the expression in brackets in Equation (29) is positive and therefore $P$ is positive. $P$ is the value of the flexibility obtained with the banking. This value tends to 0 when $n$ tends to infinity. It is equal to zero when $A^{\prime}=(1+r) A$.

In the appendix (see 9.2) the impact of banking on the mark-up is studied.

Lemma 2. The equilibrium quantity $q^{*}$ defined by the Equation (11) (respectively $q^{\prime *}$ defined by the Equation (12)) is increasing (respectively decreasing) in the discount rate, $r$.

Proof. $\frac{\partial q^{*}}{\partial r}=\frac{2(b-c)}{(n+1)(2+r)^{2} d}-\frac{A+A^{\prime}}{n(2+r)^{2} \epsilon}$. Since by assumption Equation (9) holds then $A+A^{\prime}<\frac{n}{n+1} \frac{2(b-c) \epsilon}{d} \Leftrightarrow \frac{\partial q^{*}}{\partial r}>0$. Furthermore $\frac{\partial q^{\prime *}}{\partial r}=-\frac{\partial q^{*}}{\partial r}$.

\section{Analysis of $\mathrm{CO}_{2}$ prices.}

\subsection{Initial allocations and banking}

Let us define $\lambda=\frac{A^{\prime}}{A}$. In Figure 1 , excluding the area where $\lambda>1$ (since by assumption $A^{\prime}<A$ ) three zones are represented.

1. The amount of permits allocated are such that banking is not optimal, ie. $A O A$ is not verified. This is achieved when $A$ and $\lambda$ are located in the shaded region. This case occurs when $A$ is sufficiently small. 
2. If $A>\frac{n}{n+1} \frac{(b-c) \epsilon}{d}$ for all $\lambda$ the banking is optimal ie. AOA is verified.

3. If $A>\frac{n}{n+1} \frac{2(b-c) \epsilon}{d}$ for all $\lambda$ firms will never be constrained in emission and hence $\sigma=\sigma^{\prime}=0$.

Lemma 3. The domain of $A$ and $A^{\prime}$ such as there are $A O A$ is decreasing in $r$. By contrast, the discount rate has no impact on the fields of $A$ and $A^{\prime}$ for which firms are "quota constrained".

Proof. $\frac{\partial\left[(1+r) A-\frac{n}{n+1} \frac{(b-c) r \epsilon}{d}\right]}{\partial r}=A-\frac{n}{1+n} \frac{(b-c) \epsilon}{d}$. Then $\frac{\partial\left[(1+r) A-\frac{n}{n+1} \frac{(b-c) r \epsilon}{d}\right]}{\partial r}<0$ if $A<$ $\frac{n}{1+n} \frac{(b-c) \epsilon}{d}$. Since by assumption $A^{\prime}<A,(9)$ yields $A<\frac{n}{1+n} \frac{(b-c) r \epsilon}{d}<\frac{n}{1+n} \frac{(b-c) \epsilon}{d}$. In opposition $\frac{n}{n+1} \frac{2(b-c) \epsilon}{d}-A^{\prime}$ is independent of $r$. So an increase in the discount rate leads to a decrease of areas $A$ and $A^{\prime}$ where the AOA is verified.

\section{Insert figure1.gif}

Figure 1: AOA vs no AOA zones.

\section{$5.2 \quad \mathrm{CO}_{2}$ prices.}

To each region plotted in Figure 1 above, correspond $\mathrm{CO}_{2}$ prices we have plotted in Figure 2, more precisely we drew $\sigma$ and $\frac{\sigma l}{1+r}$ as a function of $A$, the number of permits allocated in the first period. Let

$$
\underline{a}=\frac{n}{n+1} \frac{(b-c) r \epsilon}{d(1+r-\lambda)}
$$

and

$$
\bar{a}=\frac{n}{n+1} \frac{2(b-c) \epsilon}{d(1+\lambda)} .
$$

1. When $A$ is less than $\underline{a}$ the banking is not optimal and the $\mathrm{CO}_{2}$ prices are defined by the Equation $(19)$ and Equation $\sqrt{20}, \sigma>\frac{\sigma \prime}{1+r}$.

2. If $A$ is greater than $\underline{a}$, then the permit price in the second period is equal to the capitalized permit price of the first period, $\sigma=\frac{\sigma \prime}{1+r}$ and, if $A$ is greater than $\bar{a}$ the firms are not constrained by emissions and consequently permit prices are zero.

Insert figure2.ppt

Figure 2: $\mathrm{CO}_{2}$ prices as a function of $A$. 
If $A^{\prime}$ increases (ceteris paribus), the price of $\mathrm{CO}_{2}$ decreases (increases $\lambda$ and hence $\underline{a}$ and $\bar{a}$ decrease). A decrease in the cost of production increases production thus emissions are increased and consequently permit prices are increased. There is the same effect when the elasticity increases 5 . If $A \in[\underline{a}, \bar{a}]$, the permit price in a competitive market is $\sigma^{*}=\frac{2(b-c) d}{(2+r)}-\frac{\left(A+A^{\prime}\right) d}{(2+r) \epsilon^{2}}$.

Lemma 4. The equilibrium price of permits for the first period, $\sigma^{*}$ (respectively second, $\sigma^{*}$ ) is decreasing in $r$ (respectively increasing).

Proof. $\frac{\partial \sigma^{*}}{\partial r}=-\frac{2(b-c)}{(2+r)^{2} \epsilon}-\frac{1+n}{n} \frac{\left(A+A^{\prime}\right)}{(2+r)^{2} \epsilon^{2}}$. Since by assumption Equation $(9)$ holds then $A+A^{\prime}<\frac{n}{n+1} \frac{2(b-c) \epsilon}{d} \Leftrightarrow \frac{\partial \sigma^{*}}{\partial r}<0$. Furthermore $\frac{\partial \sigma^{\prime *}}{\partial r}=-\frac{\partial \sigma^{*}}{\partial r}$.

\section{Effect of "set aside" or "backloading" of emis- sion certificates.}

The backloading policy is meant to be implemented only in EU-ETS second phase. This means that the two periods considered in the model must be thought as two group of years included in the same phase $8^{8}$ Two configurations must be studied.

1. A "pure backloading" case, where the quantity of permits withheld in the first period is equal to the quantity of permits supplied in the second period, and

2. A "partial backloading" case, where the quantity supplied in the second period is lower, reflecting the lower expected supply because of uncertainty on the policy (as explained in the description of backloading measures).

\section{1 "Pure backloading" case.}

If a portion $\Delta$ of the permits allocated in the first period are removed to be redistributed to the second period, the condition on $A$ and $A$ such that firms are constrained by the number of permits on the two periods combined (Equation (9)) is not changed, but the optimality condition of the banking (Equation (10)) becomes $(1+r)(A-\Delta)-\left(A^{\prime}+\Delta\right) \geq \frac{n}{n+1} \frac{(b-c) r \epsilon}{d} \Longleftrightarrow$

$$
(1+r) A-A^{\prime} \geq \frac{n}{n+1} \frac{(b-c) r \epsilon}{d}+(2+r) \Delta .
$$

\footnotetext{
${ }^{7}$ That is to say, when $\frac{1}{d}$ increases.

${ }^{8}$ The fact that borrowing is partially allowed does not modify the conclusions from the model, since the quantities supplied in advance are completely equivalent to a higher cap in the given period.
} 
Setting aside permits has no impact on the tightness of the constraint but may increase the area where the banking is not optimal.

A policy that may have no effect. If the quantity of permits withheld in the first period is too small then backloading has no impact on $\mathrm{CO}_{2}$ prices. Indeed, if initially the optimality condition of the banking (Equation (10)) is verified, for all set aside $\Delta \leq \bar{\Delta}$ where

$$
\bar{\Delta}=\left(\max \frac{(1+r) A-A^{\prime}}{2+r}-\frac{n}{n+1} \frac{(b-c) r \epsilon}{(2+r) d}, 0\right),
$$

firm still bank permits in the first period in order to use them during the second period. The threshold $\bar{\Delta}$ is equal to the amount of permits that would be efficiently banked in the absence of any set aside.

Figure 3.a presents the impact of a set aside $\Delta_{1}$ such as $\Delta_{1}<\bar{\Delta}$. Thus, when the constraint of the first period is tightened ( $A$ is reduced by $\Delta_{1}$ ) and the constraint of second period is released by $\Delta_{1}$ then there is a translation to the right of $\underline{a}$ (which becomes $\underline{a}_{1}$ ) as well as a translation towards the left of $\bar{a}$ (which becomes $\left.\bar{a}_{1}\right)$. The equilibrium is unchanged $\left(\sigma_{1}=\sigma^{*}\right.$ and $\left.\sigma_{1}^{\prime}=\sigma^{* \prime}\right)$.

Insert figure 3.a.ppt

Figure 3.a: Impact of backloading on $\mathrm{CO}_{2}$ prices where $\Delta=\Delta_{1}<\bar{\Delta}$

A policy that creates inefficiencies. If the quantity of permits withheld in the first period is higher, AOA can not be verified and thus the policy may create inefficiencies. Indeed, if $\Delta>\bar{\Delta}$ banking is no longer optimal. For exemple, in Figure 3.b, $\Delta=\Delta_{2}>\bar{\Delta}$. In this case $\underline{a}$ and $\bar{a}$ respectively become $\underline{a}_{2}$ and $\bar{a}_{2}$ and the new equilibrium is $\sigma_{2}>\sigma^{*}$ and $\sigma_{2}^{\prime}>\sigma^{* \prime}$.

Insert figure 3.b.ppt

Figure 3.b: Impact of "backloading" on $\mathrm{CO}_{2}$ prices where $\Delta=\Delta_{2}>\bar{\Delta}$

Therefore, a policy of "pure backloading" has either no effect on $\mathrm{CO}_{2}$ prices or increases them such as the AOA does not longer hold. Is a "partial backloading" policy would increase the $\mathrm{CO}_{2}$ price in the first period?

\section{2 "Partial backloading" case.}

If backloading is such that the number of additional permit redistributed in the second period is equal to $\beta \Delta$ then the optimality condition of the banking (Equation (32) ) can be rewritten

$$
(1+r) A-A^{\prime} \geq \frac{n}{n+1} \frac{(b-c) r \epsilon}{d}+(1+\beta+r) \Delta
$$


which gives the threshold:

$$
\bar{\Delta}_{\beta}=\max \left(\frac{(1+r) A-A^{\prime}}{1+\beta+r}-\frac{n}{n+1} \frac{(b-c) r \epsilon}{(1+\beta+r) d}, 0\right) .
$$

If the number of permits withdrawn the first period is less than $\bar{\Delta}_{\beta}$ the "partial backloading" policy has no effect. In contrast, if this number is greater than $\bar{\Delta}_{\beta}$ it creates inefficiencies.

If a portion of the permits allocated in the first period is removed to be reinjected in whole or in part in the second period, the area $\left(A, A^{\prime}\right)$ such that it is optimal to store permits between the two periods is widened. It is possible that the decrease of permits allocated in the first period is so high that banking permits between the two periods is no longer optimal. In the "pure backloading" case, the permit prices are not modified, provided that the quantity withheld is lower than a given threshold. Otherwise, the borrowing constraint becomes active and Hotelling's rule does not apply anymore. Present value permit price in the second phase is lower than the price in first phase. This situation is unlikely when the number of permits injected the second period is less than the number of permits withdrawn the first period (that is to say $\beta<1$ ). In the "partial backloading" case, prices rise, provided that the quantity withheld is lower than another threshold, given that the total of allowances supplied is modified in comparison with the "pure backloading" case. This means that "backloading" may succeed in propping-up prices, due to expectations $!^{9}$

\section{Conclusion}

This paper has analyzed the joint equilibrium of an emissions permits market and the output market whose emissions are capped. Banking allows firms to minimize their compliance costs as long as it is optimal to bank. We provide the conditions for which this is true, implying that the permit price follows Hotelling's rule. Those conditions depend on the values of demand, cost, emission and allocations parameters. When the conditions are not fulfilled, the present value of second period permit price is lower than first period price and no permits are banked. Our model thus allows to understand how backloading proposals are supposed to work on the EU-ETS, and under which conditions they may distort the intertemporal efficiency

\footnotetext{
${ }^{9}$ When the parameters of the output market take different values at each period (see Appendix 9.3 and banking is not optimal, the first period permit price may be higher than the present value of the second period price, even though the cap is decreasing. Such a case is possible if, for example, on the product market, demand in the second period is lower than the one in the first, or if expected second period emission rate is lower than in the first period. This last example may happen if for instance a strong development of renewables is expected between the two periods.
} 
of the market. Our model provides elements on how to make those adjustments taking into account structural of the fundamentals in the output market of firms under environmental constraints.

Acknowledgments A. Creti gratefully acknowledges nancial support from the Ecole Polytechnique ChairEDF-Sustainable Development, and the Business Sustainability Initiative at Europlace Institute of Finance.

\section{References}

Carmona, R., Fehr, M., Hinz, J., 2009, "Optimal Stochastic Control and Carbon Price Formation", SIAM Journal on Control and Optimization 48(4), 2168-2190.

Chevalier, J., 2012, "Carbon Price Drivers: An Updated Literature Review", Journal of Economic Surveys 26 (1), 157-176.

Cronshaw, M.B., Kruse, J.B., 1996, "Regulated Firms in Pollution Permit Markets with Banking", Journal of Regulatory Economics 9(2), 179-189.

Ellerman, A.D., and Montero, J.P. 2007, "The Efficiency and Robustness of Allowance Banking in the U.S. Acid Rain Program", Energy Journal 28(4), 205-233.

European Commission, 2012, "The state of the European carbon market in 2012".

Hintermann, B., 2009, "Market Power and Windfall Profits in Emission Permit Markets", CEPE Working Paper No. 62.

Hinz, J., Novikov, A., 2010, "On fair pricing of emission-related derivatives", Bernoulli 16(4), 1240-1261.

Kling, C., Rubin, J., 1997, "Bankable permits for the control of environmental pollution", Journal of Public Economics 64, 101-115.

Maeda, A., 2004, "Impact of Banking and Forward Contracts on Tradable Permit Markets", Environmental Economics and Policy Studies 6(2), 81-102.

Montero, J.-P., Liski, M., 2005, "A note on market-power in emissions permits market with banking", Environmental \& Resource Economics, 31: 159-173.

Montero, J.-P., 2009, "Market power in pollution permits markets" The Energy Journal 30, $115-142$.

Peluchon, B., 2011, "Banking and borrowing in emissions trading systems", EDF Working Paper. 
Requate, T., 2005, "Environmental Policy under Imperfect Competition: A Survey", Economics working paper / Christian-Albrechts-Universität Kiel, Department of Economics, No. 2005,12 .

Rubin, J., 1996, "A model of intertemporal emission trading, banking, and borrowing", Journal of Environmental Economics and Management 31, 269-286.

Schennach S.M., 2000, "The Economics of Pollution Permit Banking in the Context of Title IV of the 1990 Clean Air Act Amendments", Journal of Environmental Economics and Management 40, 189-210.

Taschini, L., 2009, "Environmental economics and modeling marketable permits: A survey",. Asian Pacific Financial Markets 17 (4), 325-343, 2010.

\section{Appendix}

\subsection{Evolution of $\mathrm{CO} 2$ price}

Insert Figure4.gif

Figure 4: Prix spot EUA in €/t (Source - Point Carbon )

\subsection{Effect of banking on mark-up rate.}

Without banking, the mark-up rate of the first period is given by

$$
m=\frac{p-c-\epsilon \sigma_{n b}}{c+\epsilon \sigma_{n b}}=\frac{d A}{n b \epsilon-(1+n) d A},
$$

and the mark-up rate of the second period

$$
m^{\prime}=\frac{p^{\prime}-c-\epsilon \sigma_{n b}^{\prime}}{c+\epsilon \sigma_{n b}^{\prime}}=\frac{d A^{\prime}}{n b \epsilon-(1+n) d A^{\prime}} .
$$

These rates are increasing functions of the number of permits and decreasing functions of $n$ and of the emission factor $\epsilon$. With banking, the mark-up rate of the first period is given by

$$
m^{*}=\frac{n r(b-c) \epsilon+(1+n) d\left(A+A^{\prime}\right)}{(1+n)\left[n(2 b+c r) \epsilon-(1+n) d\left(A+A^{\prime}\right)\right]}
$$

and the mark-up rate of the second period is equal to

$$
m^{\prime *}=\frac{n r(b-c) \epsilon-(1+n) d\left(A+A^{\prime}\right)}{(1+n)\left[n(c r-2(1+r) b) \epsilon+(1+n)(1+r) d\left(A+A^{\prime}\right)\right]} .
$$


These rates are decreasing functions of the number of permits and tend obviously to 0 as $n$ tends to infinity. Combining Equations (36) and (38) yield $m>m^{*}$ if Equation (10) is verified. As a result, store permits in the first period reduces the mark-up of the first period. What is the effect of storage on the mark-up of the second period? Combining Equations (37) and (39) yields $m^{\prime}<m^{\prime *}$ if $A>S$ where

$$
S=\frac{n^{2}}{n+1} \frac{b(b-c) r \epsilon^{2}}{d\left((1+n) d r A^{\prime}+b n \epsilon\right)}+\frac{A^{\prime}\left(n(1+r) b \epsilon-A^{\prime}(1+n) d r\right)}{(1+n) d r A^{\prime}+b n \epsilon} .
$$

We show that if $A<\frac{n}{1+n} \frac{b \epsilon}{d}$ (true from 15 ) then 10 implies $A>S$. Therefore, store permits in the first period increases the mark-up of the second period.

\subsection{General case}

We consider the case in which $c^{\prime} \neq c, b^{\prime} \neq b, d^{\prime} \neq d$ and $e_{0} \neq e_{0}^{\prime}$. If the number of permits $A+A^{\prime}$ is such as

$$
A+A^{\prime} \leqslant \frac{n}{n+1}\left(\frac{(b-c) d^{\prime} \epsilon+\left(b^{\prime}-c^{\prime}\right) d \epsilon^{\prime}}{d d^{\prime}}-\frac{d^{\prime}\left(e_{0}-\epsilon\right) \epsilon+d\left(e_{0}^{\prime}-\epsilon^{\prime}\right) \epsilon^{\prime}}{d d^{\prime}}\right)
$$

then the firms are constrained. If furthermore

$$
(1+r) d \epsilon^{2} A-d^{\prime} \epsilon^{2} A^{\prime}>\frac{n}{n+1}\left[(1+r)\left(b-c-e_{0}\right) \epsilon^{\prime}-\left(b^{\prime}-c^{\prime}-e_{0}^{\prime}\right) \epsilon+r \epsilon \epsilon^{\prime}\right] \epsilon \epsilon^{\prime}
$$

there is an opportunity to store permits and at equilibrium the abscence of arbitrage opportunities, AOA is characterized by (AOA) and equilibrium is defined by 


$$
\begin{aligned}
\sigma= & \frac{(b-c) d^{\prime} \epsilon+\left(b^{\prime}-c^{\prime}\right) d \epsilon^{\prime}}{d^{\prime} \epsilon^{2}+d(1+r) \epsilon^{\prime 2}-\frac{n+1}{n} \frac{\left(A+A^{\prime}\right) d d^{\prime}}{d^{\prime} \epsilon^{2}+d(1+r) \epsilon^{\prime 2}}} \\
& -\frac{d^{\prime}\left(e_{0}-\epsilon\right) \epsilon+d\left(e_{0}^{\prime}-\epsilon^{\prime}\right) \epsilon^{\prime}}{d^{\prime} \epsilon^{2}+d(1+r) \epsilon^{\prime 2}}, \\
\sigma^{\prime}= & (1+r) \sigma, \\
\bar{z}= & \frac{(1+r) d \epsilon^{\prime 2} A-d^{\prime} \epsilon^{2} A^{\prime}}{n\left(d^{\prime} \epsilon^{2}+d(1+r) \epsilon^{\prime 2}\right)}+\frac{\left[\left(b^{\prime}-c^{\prime}\right) \epsilon-(1+r)(b-c) \epsilon^{\prime}\right] \epsilon \epsilon^{\prime}}{(n+1)\left(d^{\prime} \epsilon^{2}+d(1+r) \epsilon^{\prime 2}\right)} \\
& +\frac{\left[(1+r) e_{0} \epsilon^{\prime}-\left(r \epsilon^{\prime}+e_{0}^{\prime}\right) \epsilon\right] \epsilon \epsilon^{\prime}}{(n+1)\left(d^{\prime} \epsilon^{2}+d(1+r) \epsilon^{\prime 2}\right)} \\
q= & \frac{d^{\prime}\left(A+A^{\prime}\right) \epsilon}{n\left(d^{\prime} \epsilon^{2}+d(1+r) \epsilon^{\prime 2}\right)}-\frac{\left[\left(b^{\prime}-c^{\prime}\right) \epsilon-(1+r)(b-c) \epsilon^{\prime}\right] \epsilon^{\prime}}{(n+1)\left(d^{\prime} \epsilon^{2}+d(1+r) \epsilon^{2}\right)} \\
& -\frac{\left[(1+r) e_{0} \epsilon^{\prime}-\left(r \epsilon^{\prime}+e_{0}^{\prime}\right) \epsilon\right] \epsilon^{\prime}}{(n+1)\left(d^{\prime} \epsilon^{2}+d(1+r) \epsilon^{\prime 2}\right)}, \\
q^{\prime}= & \frac{d(1+r)\left(A+A^{\prime}\right) \epsilon^{\prime}}{n\left(d^{\prime} \epsilon^{2}+d(1+r) \epsilon^{\prime 2}\right)}+\frac{\left[\left(b^{\prime}-c^{\prime}\right) \epsilon-(1+r)(b-c) \epsilon^{\prime}\right] \epsilon}{(n+1)\left(d^{\prime} \epsilon^{2}+d(1+r) \epsilon^{\prime 2}\right)} \\
& +\frac{\left[(1+r) e_{0} \epsilon^{\prime}-\left(r \epsilon^{\prime}+e_{0}^{\prime}\right) \epsilon\right] \epsilon}{(n+1)\left(d^{\prime} \epsilon^{2}+d(1+r) \epsilon^{\prime 2}\right)}
\end{aligned}
$$

If the condition (41) does not hold then the equation of $\mathrm{AOA}$ is not verified and the equilibrium is defined by

$$
\begin{aligned}
\sigma_{n b} & =\frac{b-c}{\epsilon}-\frac{(1+n)}{n} \frac{d A}{\epsilon^{2}}-\frac{e_{0}-\epsilon}{\epsilon} \\
\sigma_{n b}^{\prime} & =\frac{b^{\prime}-c^{\prime}}{\epsilon^{\prime}}-\frac{(1+n)}{n} \frac{d A^{\prime}}{\epsilon^{\prime 2}}-\frac{e_{0}^{\prime}-\epsilon^{\prime}}{\epsilon^{\prime}} \\
q_{n b} & =\frac{A}{n \epsilon} \\
q_{n b}^{\prime} & =\frac{A^{\prime}}{n \epsilon^{\prime}}
\end{aligned}
$$

Notice that the mark-up rates are the same as in the case without abatement cost. The area of AOA is larger when there are abatement costs. The possibility to switch technology bearing abatement costs in order to emit less emission provides flexibility to the firm. As a result, permit prices after switching technologies are weaker than before and the area where prices of $\mathrm{CO}_{2}$ permits are zero is wider. 


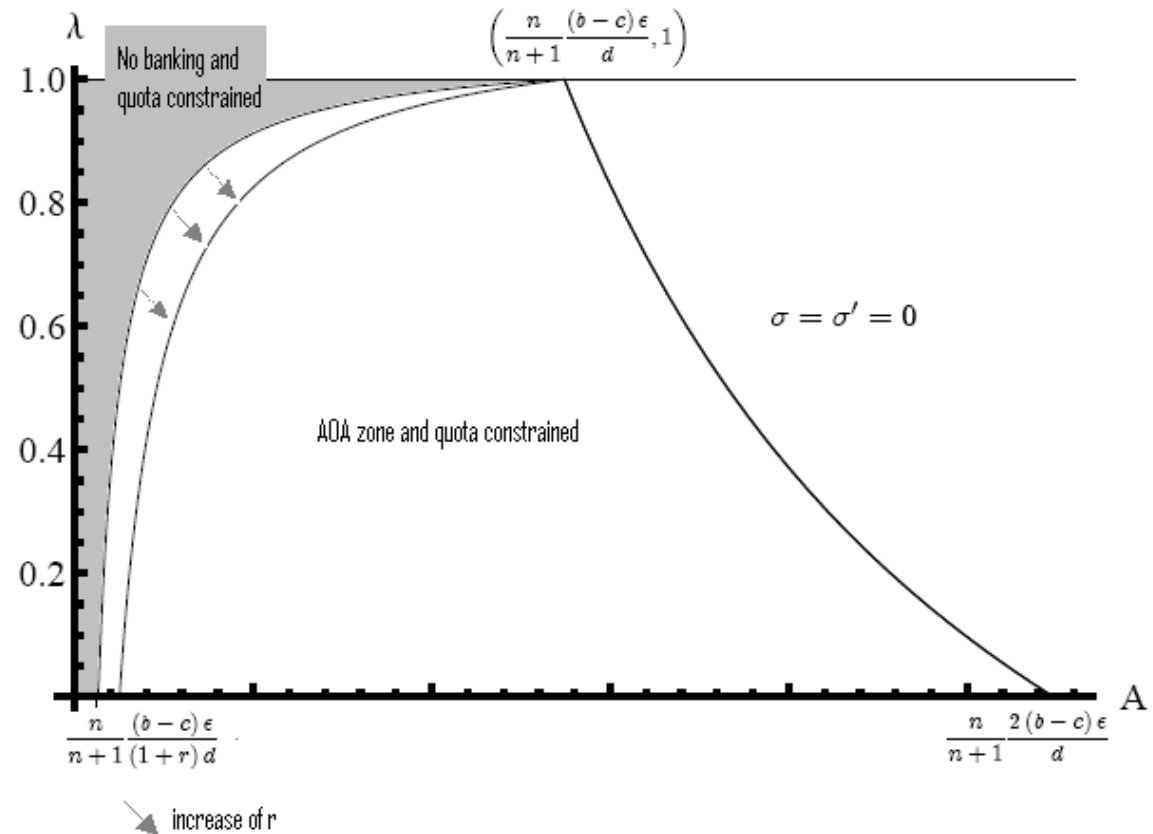

Figure 1: AOA vs no AOA zones.

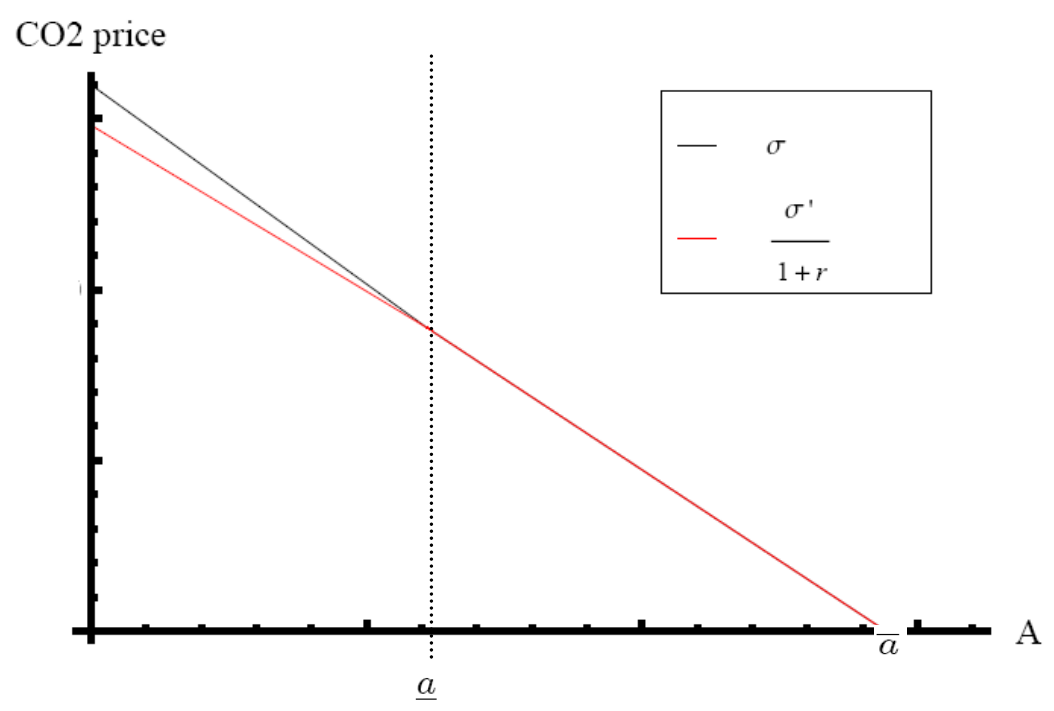

Figure 2: $\mathrm{CO}_{2}$ prices as a function of $A$. 


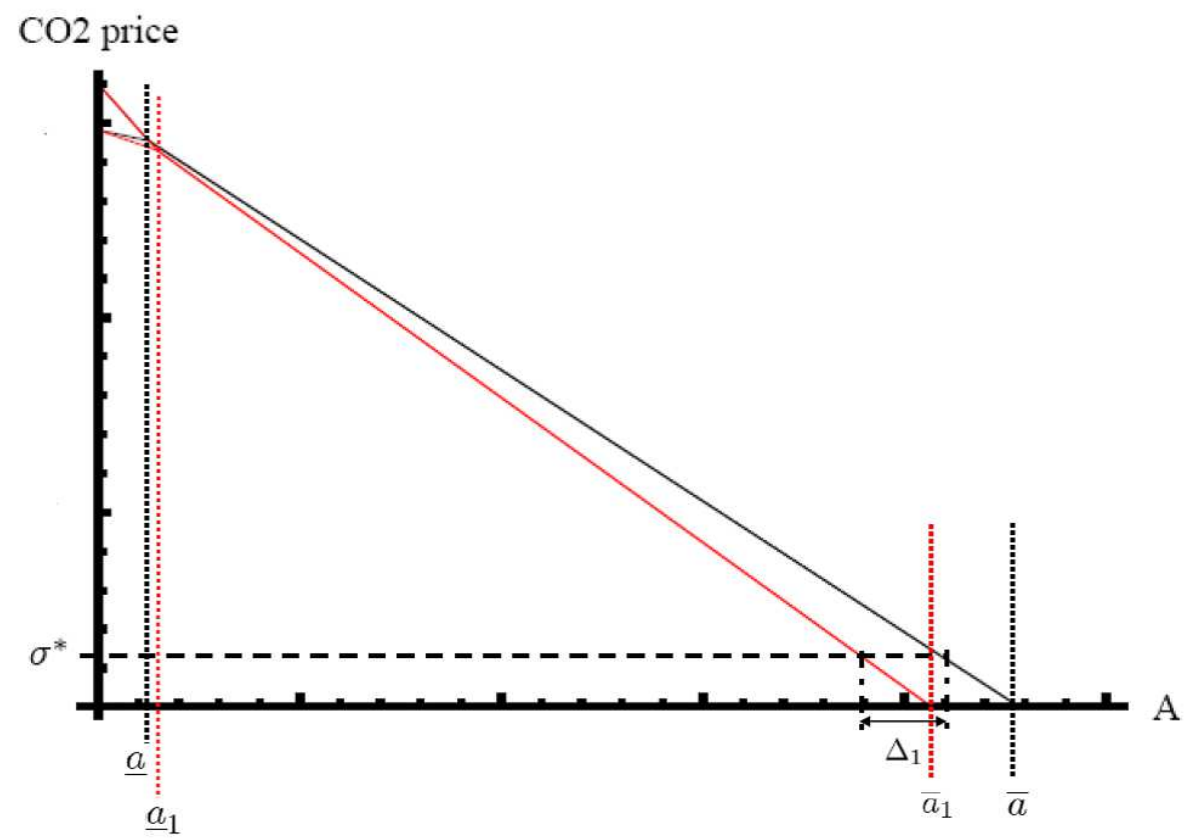

Figure 3.a: Impact of backloading on $\mathrm{CO}_{2}$ prices where $\Delta=\Delta_{1}<\bar{\Delta}$

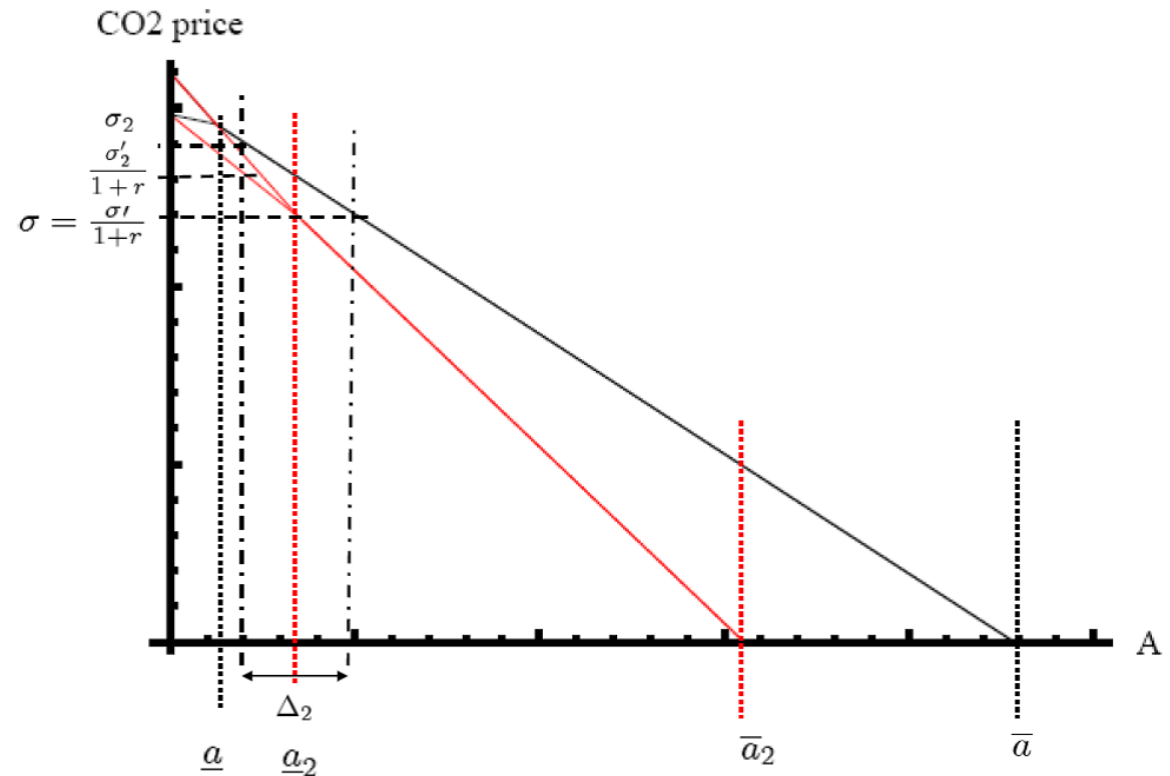

Figure 3.b: Impact of "backloading" on $\mathrm{CO}_{2}$ prices where $\Delta$ $=\Delta_{2}>\bar{\Delta}$ 


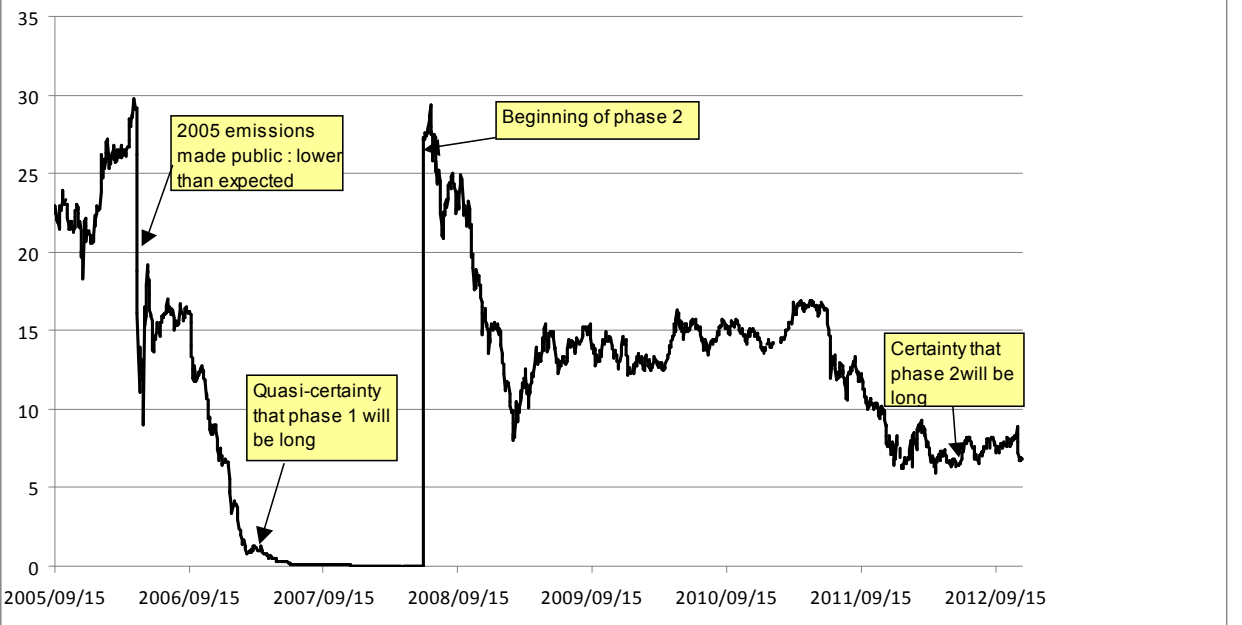

Figure 4: Prix spot EUA in $€ / t$ (Source - Point Carbon ) 